\title{
Mean Three-Dimensional Circulation in the Northeast Tropical Pacific*
}

\author{
WILLIAM S. KeSSLER \\ NOAA/Pacific Marine Environmental Laboratory, Seattle, Washington
}

(Manuscript received 5 July 2001, in final form 26 December 2002)

\begin{abstract}
Historical XBT data are used to construct a mean climatology of the three-dimensional geostrophic circulation in the northeast tropical Pacific (southwest of Mexico and Central America) and are diagnosed based on linear dynamics forced with satellite scatterometer winds. Unlike the familiar central tropical Pacific, where the zonal scales are very large and the wind forcing nearly a function of latitude alone, the North Pacific east of about $120^{\circ} \mathrm{W}$ is strongly influenced by wind jets blowing through gaps in the Central American cordillera. The curl imposed by these wind jets imprints on the ocean, producing a distinctive pattern of thermocline topography and geostrophic currents that are consistent with the Sverdrup balance. Notably, the weakening of the North Equatorial Countercurrent near $110^{\circ} \mathrm{W}$ is due to the wind forcing. Given the observed stratification and wind stress curl, planetary vorticity conservation also determines the distribution of vertical velocity in the region, with about $3.5 \mathrm{~Sv}\left(\mathrm{~Sv} \equiv 10^{6} \mathrm{~m}^{3} \mathrm{~s}^{-1}\right)$ of upwelling through the base of the thermocline under the Costa Rica Dome. This upwelling is associated with stretching of the water column under the dome, which thereby causes the northern "Subsurface Counter Current" (SSCC or Tsuchiya Jet) to turn away from the equator; about half the transport of the SSCC upwells through the thermocline via this mechanism. This may be part of the process by which intermediate-depth water, flowing into the Pacific from the south, is brought to the surface and into the Northern Hemisphere.
\end{abstract}

\section{Introduction}

Although the northeastern tropical Pacific is close to a well-populated coast, is crossed by often-traveled shipping lanes, and is the long-term site of major fisheries, there has been relatively little attention paid to the dynamics that control the mean circulation in the region since the pioneering investigations done at the Scripps Institution of Oceanography more than 30 years ago (Cromwell 1958; Wyrtki 1964, 1966, 1967). Much more work has studied the ocean responses to the sometimes-spectacular Central American mountain-gap wind events that can generate intense mixing and eddy activity over periods of a few days (Roden 1961; Clarke 1988; McCreary et al. 1988; Barton et al. 1993; Giese et al. 1994; Trasviña 1995). Others have looked at the effects of propagating, nonlinear eddies produced by strong currents near the coast (Umatani and Yamagata 1991; Hansen and Maul 1991).

In the present paper, historical expendable bathythermograph (XBT) data are used to define the mean

\footnotetext{
* Pacific Marine Environmental Laboratory Contribution Number 2351.
}

Corresponding author address: William S. Kessler, NOAA/Pacific Marine Environmental Laboratory, 7600 Sand Point Way NE, Seattle, WA 98115.

E-mail: kessler@pmel.noaa.gov thermal field, which permits the vertical structure of the geostrophic currents in the region to be estimated. This structure is diagnosed based on linear dynamics forced by highly spatially resolved satellite scatterometer winds. The mean signature of the mountain-gap winds is found to be the crucial forcing element, as others have found for the short-timescale episodes. However, it is argued here that the mean ocean response can be largely understood without reference to the nonlinear mechanisms that are invoked for the high-frequency eddies. While it is likely that these nonlinear processes rectify into both the mean and the annual cycle, the first step in understanding the effect of the winds on the ocean is to quantify the linear effect of the mean forcing, which is the aim of the present study.

The importance of the mountain-gap winds emphasizes the difference between the eastern Pacific and the wide open spaces of the central tropical Pacific, where the familiar zonal currents (the westward North and South Equatorial Currents, and the eastward North Equatorial Countercurrent) that enter and leave this region have been well studied (Wyrtki and Kilonsky 1984; Johnson et al. 1988; Taft and Kessler 1991; Picaut and Tournier 1991; Reverdin et al. 1994; Lagerloef et al. 1999; Johnson et al. 2002). In the central Pacific, mean winds are nearly a function of latitude alone, and a useful diagnosis of the ocean response can be gained by interpretation based on linear, Sverdrupian dynamics 


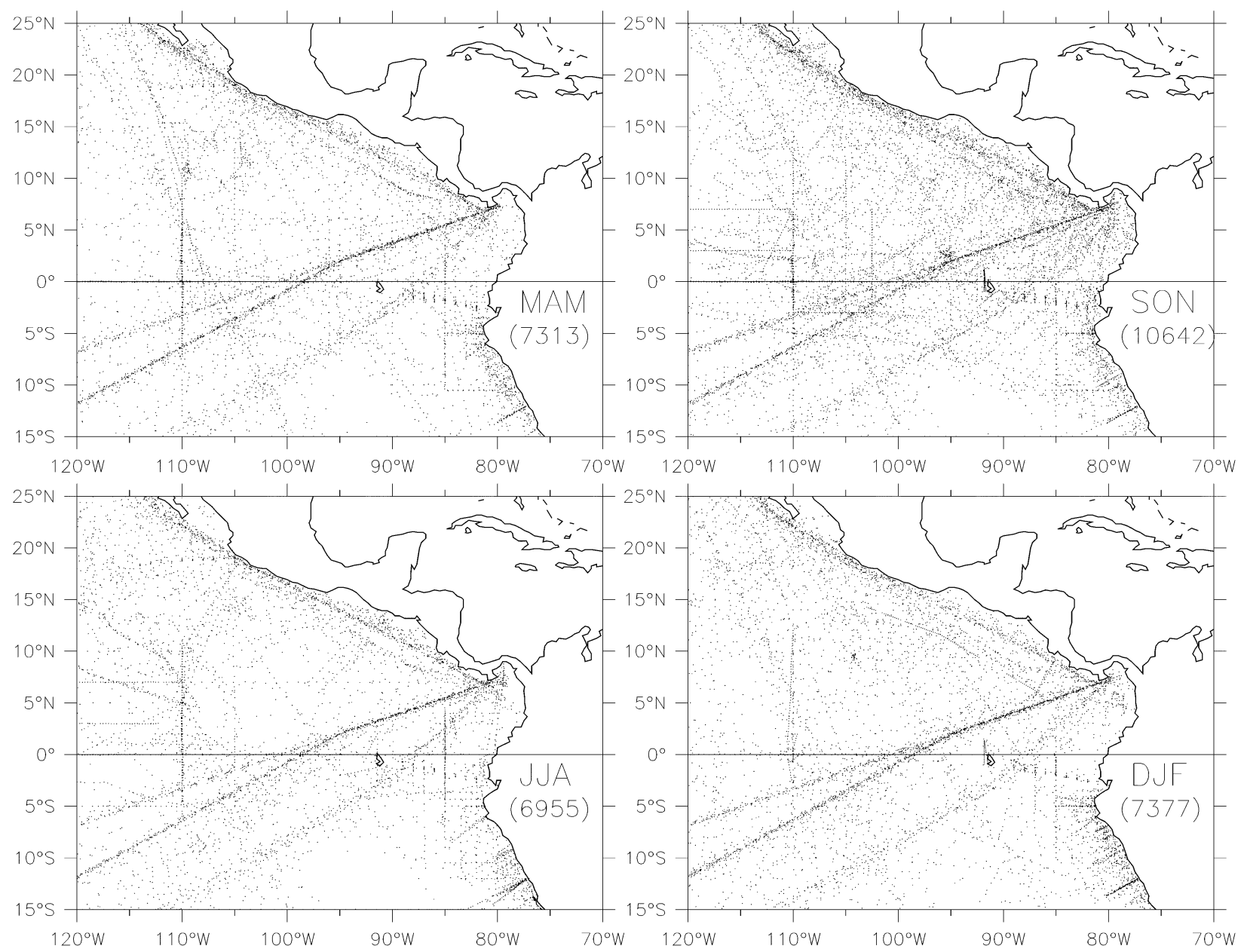

FIG. 1. Distribution of XBT data, stratified by season. The number in parenthesis under each season indicator gives the total number of profiles in the region during that period.

(Sverdrup 1947; Meyers 1980; Kessler and Taft 1987; McPhaden and Fine 1988; Landsteiner et al. 1990). By contrast, in the east, the effect of the Central American cordillera funneling winds through narrow passes makes the wind field much more complicated, and likewise so are the ocean thermal and current structures, but we argue here that the wind-driven imprint on the ocean is still controlled by similar dynamical mechanisms.

A larger goal, not achieved here, is to "close" the circulation in the eastern tropical Pacific by understanding the interconnections among the major central Pacific currents at the eastern boundary. A convincing closure will probably include the use of tracer fields to establish the pathways of flows that are too slow, too deep, too intermittent, too close to the coast, or are the result of mixing and thus are difficult to diagnose based on geostrophy as done here. However, the geostrophic dynamics studied here strongly imply that these interconnections are three-dimensional, in particular that the off-equatorial northeastern tropical Pacific is a region of significant upwelling of subthermocline water into the surface layer. If this is borne out by subsequent analyses, it will be significant because the tropical upwelling usually considered important (that in the equatorial cold tongue) arises primarily from within the thermocline and above. Thus the regional circulation studied here may play a role in basin-scale water mass exchanges.

\section{Data}

\section{a. XBT data}

The principal dataset used in this study is the historical XBT compilation of Donoso et al. (1994). These profiles originated from earlier compilations produced principally by the National Ocean Data Center, the Joint Environmental Data Center at Scripps, and the Global Subsurface Data Center in Brest, France. A total of 21204 profiles were available in the study region $0^{\circ}-25^{\circ} \mathrm{N}$ and from $120^{\circ} \mathrm{W}$ to the American coast. Figure 1 shows that the profiles were primarily organized along the major shipping routes. The main concentration of profiles were tak- 
en during 1979 through 1992, with smaller numbers after that date. About one third of the profiles were made during September-November, but any potential bias introduced thereby in the mean is alleviated by taking the mean of the average annual cycle, as described below. Donoso et al. (1994) describe the objective and subjective quality control procedures used to flag questionable observations and produce a research-quality dataset. Only data points that they found to be acceptable were used in this study.

The irregularly distributed profiles were mapped to a regular $1^{\circ}$ lat by $1^{\circ}$ lon by $10 \mathrm{~m}$ by climatological-month grid in two steps. First, the temperature data in each individual profile were linearly interpolated to $10-\mathrm{m}$ depth intervals from the surface to $450 \mathrm{~m}$ (on average, each profile had about 41 samples in the upper $450 \mathrm{~m}$ ). Second, in a separate calculation at each $10-\mathrm{m}$ level $z_{0}$, the irregularly spaced temperatures were mapped onto the $(x, y$, $\left.z_{0}, t\right)$ grid using a Gaussian-weighted three-dimensional mapping (Kessler and McCreary 1993), with scales of $2^{\circ}$ lon, $1^{\circ}$ lat, and 2 months. The region of influence of each observation was limited to where its weighting was greater than $e^{-4}$, that is, to twice the scale distance from the center of each grid box. Only the month was considered in the gridding, not the year, to produce a climatological average annual cycle. In the present study of the mean circulation, the average of the 12 gridded climatological months is taken as the overall mean.

Although some earlier XBT-based climatologies of the entire tropical Pacific used coarser grid spacings [e.g., Kessler (1990), who mapped onto a $5^{\circ}$ lon by $2^{\circ}$ lat grid], the short spatial scales of the phenomena of interest in this region required higher resolution, and the profile distribution in the new compilation was dense enough to justify a $1^{\circ}$ by $1^{\circ}$ spacing. Each $1^{\circ}$ by $1^{\circ}$ grid box contained, on average, more than 24 profiles during the year, spread over an average of 7.4 months. The gridded temperature climatology was checked by comparison against other sources, including the Reynolds SST (Reynolds and Smith 1994) and time series from the Tropical Atmosphere Ocean (TAO) mooring array (Hayes et al. 1991; McPhaden et al. 1998).

Dynamic height relative to a $450-\mathrm{m}$ reference level was found from the gridded temperatures via a mean $T-S$ relation constructed from the Levitus et al. (1994) atlas, and geostrophic currents were found from centered differences of the dynamic heights.

\section{b. Scatterometer wind data}

Winds are used in this study to estimate Ekman pumping and the Sverdrup balance. Since the winds in this region are known to have small spatial and temporal scales (Chelton et al. 2000a,b), especially in the case of the mountaingap wind jets that will be seen to have great importance here, and because these calculations require spatial derivatives of the winds, excellent sampling is a necessity. This points to the utility of satellite scatterometer winds that can resolve the wind jets better than any in situ or presentgeneration reanalysis wind product (Freilich and Vanhoff 2001, unpublished manuscript; Chelton and Freilich 2001, unpublished manuscript).

The Quikscat satellite carrying a SeaWinds scatterometer (referred to here as Quikscat) was launched in June 1999 and its operational products became available in late July 1999. The satellite circles the earth in a 4day repeat, sun-synchronous orbit with a spacing of $6.3^{\circ}$ at the equator, sampling a swath $1600 \mathrm{~km}$ wide centered on its ground track. Because of the complex way the north- and south-going swaths overlap over time, temporal sampling at any location becomes uneven, leading to an inhomogeneous pattern of sampling errors that tend to be largest at latitudes between $20^{\circ}$ and $30^{\circ}$ (Schlax et al. 2001). The swath stress components and scalar wind speed were gridded according to the method of Schlax et al. (2001), using a loess smoothing algorithm which is analogous to the filtering properties of a $2^{\circ}$ lon, $0.5^{\circ}$ lat and 15 -day block average. The average of the first year of these smoothed fields (15 August 1999-9 August 2000) was taken to represent the longterm mean.

Fortuitously, winds during this single year in this region were reasonably typical of the decade-long climatology, as determined by comparing the one year of Quikscat winds to the average annual cycles of stress components constructed from the TAO moorings along $110^{\circ}$ and $95^{\circ} \mathrm{W}$ (whose record lengths ranged from 7 to 17 years). Visually these time series are similar, and a signal/noise $(\mathrm{S} / \mathrm{N})$ measure of the difference is the variance of the Quikscat stress components divided by the variance of the TAO - Quikscat difference. At both longitudes, the worst $\mathrm{S} / \mathrm{N}$ (about 1) were for the zonal component near the equator, and in general the zonal component ( $\mathrm{S} / \mathrm{N}$ about 3-4 away from the equator) was almost always worse than the meridional component (S/N about 5-10). The mean curl terms (which, for the buoy winds, can only be calculated as differences between relatively widely separated moorings) were also similar. Wind stress curl from Quikscat was also compared with mean curls calculated from other wind products that have much longer records [The Florida State University (FSU) ship-based winds, European Research Satellite (ERS) winds, and European Centre for Medium-Range Weather Forecasts (ECMWF) reanalysis winds]. None of these showed differences that would contradict the conclusions found here; in particular the ERS mean curl over 1991-99 was very similar to the Quikscat 1-yr mean; however, the Quikscat winds were available closer to the coast, which is important here where near-coastal winds are significant. The $\mathrm{S} / \mathrm{N}$ values and the visual comparison of the time series are encouraging enough to proceed with the assumption that the average over the single year of Quikscat winds is sufficiently representative of the long-term mean to be the best available realization of wind forcing in this region. Of course, this assumption is not perfect, and must be a source of error in the interpretation of more 
than 15 years of ocean data as a response to a single year of winds.

\section{c. Drifter data}

Surface currents estimated from drifters were used as a check on the geostrophic currents that form the main subject of this paper. Surface velocity program drifter data (Niiler et al. 1995) were obtained from the Atlantic Oceanographic and Meteorological Laboratory as 6hourly kriged positions and velocities (Hansen and Poulain 1996): 1045 drifter tracks were found in the study region; however, the distribution is not ideal since the drifter population falls off sharply closer than about $1000 \mathrm{~km}$ to the Central American coast. Nevertheless, the 6-hourly velocities were mapped to a $1^{\circ}$ by $1^{\circ}$ monthly climatological grid by the same method and with the same Gaussian scales as was done for the XBT temperature profiles described in section $2 \mathrm{a}$, which left many blank grid points near the coast.

\section{Dynamics}

The dynamics considered here are assumed to be steady and linear and described in the vertical integral by the Sverdrup balance,

$$
\beta V=\operatorname{curl}(\tau) .
$$

Upper case symbols indicate vertically integrated velocities, and $\tau$ has been divided by background density. Decomposing the meridional velocity into geostrophic and Ekman parts, where $V_{E}=-\tau^{\times} / f$, and using the identity $\operatorname{curl}(\tau / f) \equiv \operatorname{curl}(\tau) / f+\beta \tau^{\times} / f^{2}$, allows rewriting (1) as

$$
\frac{\beta}{f} V_{g}=\operatorname{curl}\left(\frac{\tau}{f}\right) .
$$

In (2) the geostrophic term on the left can be evaluated from the observed ocean data, and the term on the right from the observed winds, providing a convenient comparison between the independent XBT and scatterometer data sources.

In addition to the depth-integrated balance, we will also examine the vertical profile of vertical velocity consistent with these linear dynamics. One way to interpret (2) is that the stretching of water columns due to meridional geostrophic motion,

$$
f \frac{\partial w}{\partial z}=\beta v_{g},
$$

is balanced by the stretching due to Ekman pumping $\left[w_{E}=\operatorname{curl}(\tau / f)\right]$. An indefinite integral of (3), using the observed $v_{g}$ obtained from the XBT data, gives the vertical profile

$$
w(z)=\frac{\beta}{f} \int_{-D}^{z} v_{g} d z .
$$

On carrying this integral over the full column depth, $w(0)$ will equal $w_{E}$ if the Sverdrup balance holds. We assume that $w(-D)=0$ at the 450-m reference level used for the XBT geostrophic currents; this assumption is only justified after the fact by the reasonable agreement found in the comparison of the Sverdrup balance (2).

\section{Results}

\section{a. Description of the upper-layer thermal structure and geostrophic flow}

The east Pacific warm pool is roughly defined as the region with SST greater than $27.5^{\circ} \mathrm{C}$ east of $120^{\circ} \mathrm{W}$ (Fig. 2 , top), bounded to the south by the equatorial cold tongue, and to the northwest by cooler water of the California Current. The east Pacific warm pool lies at the east end of the band of high SST that extends across the basin from the west Pacific warm pool, under the ITCZ and along the North Equatorial Countercurrent (NECC). This band broadens in the east and becomes at least $0.5^{\circ}$ to $1^{\circ} \mathrm{C}$ warmer than any SSTs in midbasin, with warmest temperatures right at the coast of Central America. The mean axis of the ITCZ runs approximately along $9^{\circ} \mathrm{N}$, but east of $120^{\circ} \mathrm{W}$ it dips southward into the Gulf of Panama; thus the highest SSTs in the warm pool are mostly to the north of the ITCZ (and the NECC). The isolated cool spot near $9^{\circ} \mathrm{N}, 90^{\circ} \mathrm{W}$ marks the surface expression of the Costa Rica Dome, which will be discussed in detail below.

The thermocline is here represented by the depth of the $20^{\circ} \mathrm{C}$ isotherm (Z20), as has often been done in the tropical Pacific (e.g., Kessler 1990). Compared to the rest of the tropical Pacific, the thermocline under the east Pacific warm pool is sharper and shallower, generally less than $80 \mathrm{~m}$ deep (Fig. 2, bottom), but its largest vertical gradient still lies near $20^{\circ} \mathrm{C}$ and vertical excursions of isotherms within about $17^{\circ}$ to $24^{\circ} \mathrm{C}$ are highly correlated. Thermocline topography consists of two troughs (along $5^{\circ} \mathrm{N}$ and $14^{\circ} \mathrm{N}$ ) and a ridge along $9^{\circ}-$ $10^{\circ} \mathrm{N}$, representing the eastern ends of the basin-width ridge-trough system of the central Pacific. Notably, both the $14^{\circ} \mathrm{N}$ trough and (especially) the $9^{\circ} \mathrm{N}$ ridge flatten near $110^{\circ} \mathrm{W}$ before restrengthening near the coast and terminating in a nearly detached bowl and dome, respectively. In particular, the very shallow Costa Rica Dome centered near $9^{\circ} \mathrm{N}, 90^{\circ} \mathrm{W}$ appears almost as an isolated feature, where the mean depth of $20^{\circ} \mathrm{C}$ is less than $30 \mathrm{~m}$.

Mean surface dynamic height and geostrophic currents (Fig. 3) illustrate the relatively complex structures seen in this region. Consider first the western edge of the region, near $120^{\circ} \mathrm{W}$. The meridional structure here is similar to that seen over a wide region of the central Pacific (Wyrtki 1975; Wyrtki and Kilonsky 1984; Kessler and Taft 1987). The NECC flows in from the west between about $5^{\circ} \mathrm{N}$ and $10^{\circ} \mathrm{N}$, while the North Equatorial Current (NEC) and South Equatorial Current (SEC) flow 


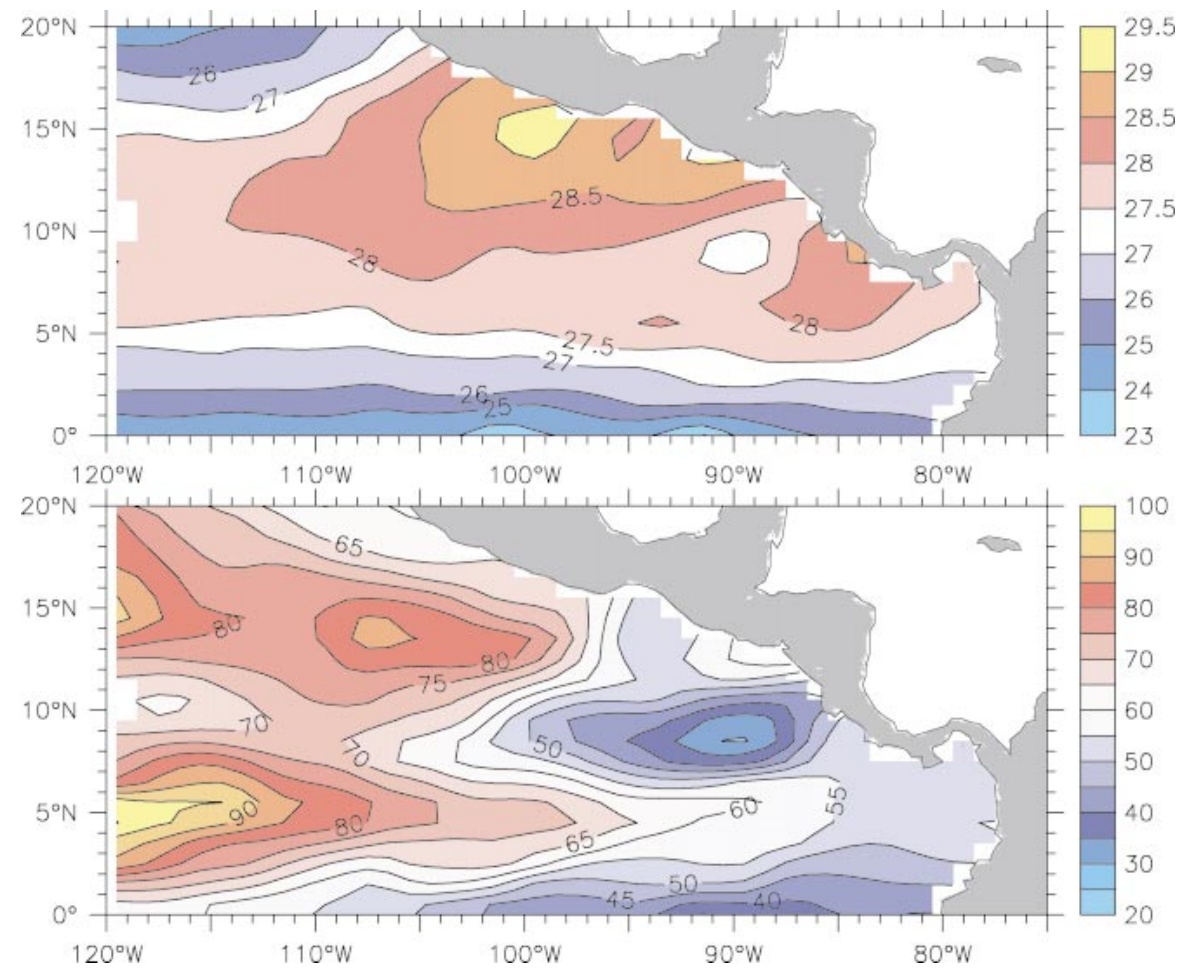

FIG. 2. Mean SST (top) and $20^{\circ} \mathrm{C}$ isotherm depth (Z20; bottom) from the XBT data. The contour interval for SST is $1^{\circ} \mathrm{C}$, with supplementary contours at $27.5^{\circ}$ and $28.5^{\circ} \mathrm{C}$. Red shading indicates warm SST, blue cool. The contour interval for Z20 is $5 \mathrm{~m}$. Red shading indicates deep thermocline; blue, shallow.

westward to the north and south of the NECC, respectively. However, east of $120^{\circ} \mathrm{W}$ the dynamic topography and currents become quite different. The NECC flowing into the region at $120^{\circ} \mathrm{W}$ is associated geostrophically with a dynamic height difference of about 8 dyn $\mathrm{cm}$ between $5^{\circ}$ and $10^{\circ} \mathrm{N}$, but by $110^{\circ} \mathrm{W}$ this has been reduced to a very weak gradient (about 2 dyn $\mathrm{cm}$ ). Considering contours of dynamic height as streamlines of the geostrophic flow shows that a large part of the NECC divides into the NEC and SEC and turns westward, not at the coast but $2000 \mathrm{~km}$ out into the basin. This is due to the flattening of the thermocline ridge at $110^{\circ} \mathrm{W}$ seen in Fig. 2 (bottom).

East of $110^{\circ} \mathrm{W}$ the surface circulation includes more meridional flow, and is dominated by the cyclonic Costa Rica Dome and the (weaker) anticyclonic eddy southwest of the Gulf of Tehuantepec. Flow around the south side of the Costa Rica Dome is not simply an eastward extension of the NECC, but instead is fed largely from the north. (However, there is a large annual cycle so

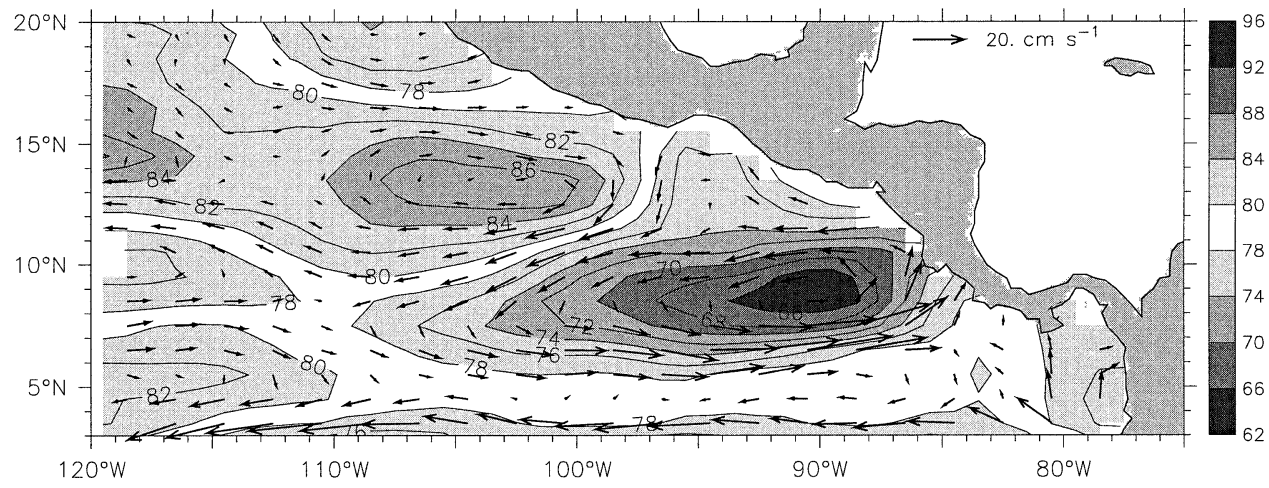

FIG. 3. Mean dynamic height and geostrophic currents at the surface relative to $300 \mathrm{~m}$, from the XBT data. Gray shading indicates dynamic heights above 80 dyn $\mathrm{cm}$ or below $78 \mathrm{dyn} \mathrm{cm}$. The contour interval is $2 \mathrm{dyn} \mathrm{cm}$. The scale vector $\left(20 \mathrm{~cm} \mathrm{~s}^{-1}\right)$ is located in the Caribbean. 
that during October-March much of the NECC does flow directly around the south side of the dome, while in the other half of the year it is virtually absent. This variation is masked in the mean field of Fig. 3.) Again noting the 78-80 dyn cm contour (white area in Fig. 3) as a streamline suggests geostrophic flow coming down the coast of Mexico, around the east side of the Tehuantepec bowl, then around the west side of the dome (as well as into the NEC). Considering these distinctive features, $115^{\circ} \mathrm{W}$ appears as the approximate eastern boundary of the central Pacific, while the region to the east represents a different regime. Diagnosing the reasons for these patterns of thermocline topography and associated geostrophic flows that are so unlike the central Pacific is a main subject of this paper.

\section{b. Circulation described by surface drifters}

A somewhat different picture is gained from the surface drifter fields. While all the geostrophic currents described above are clearly visible in the drifter maps, there are systematic differences between the two representations (Fig. 4, top and bottom rows). First, in this region the drifter-estimated NECC is faster than the geostrophic NECC by nearly a factor of 2 and does not weaken as dramatically at $110^{\circ} \mathrm{W}$. Second, the drifter $\mathrm{NEC}$ is faster than the geostrophic NEC, especially near $100^{\circ}-110^{\circ} \mathrm{W}$. Third, the drifters show a generally more westward motion in the region north of $10^{\circ} \mathrm{N}$ and west of about $105^{\circ} \mathrm{W}$. Fourth, the drifter motion is more northward than geostrophy indicates west of about $95^{\circ} \mathrm{W}$, and is more southward in the east.

Most of these differences arise because the drifters sample the total near-surface flow field, unlike Fig. 3 which shows only the geostrophic part that can be estimated from the XBT data. Ekman velocities (Fig. 4 second row) are estimated from the observed winds as $\left(u_{\mathrm{Ek}}, v_{\mathrm{Ek}}\right)=\left(\tau^{y},-\tau^{\times}\right) /\left(\rho f H_{*}\right)$, which is an average over the Ekman depth $H_{*}$. Following Ralph and Niiler (1999), this is estimated as $H_{*}=u_{*} /\left(\beta f^{1 / 2}\right)$, where $u_{*}^{2}=\left|\tau_{0}\right| / \rho$ and $\beta$ is a coefficient that Ralph and Niiler found by a least squares fit to be $0.065 \mathrm{~s}^{-1 / 2}$. In this region the mean Quikscat winds (Fig. 5) give $H_{*}$ ranging from about $40 \mathrm{~m}$ along $3^{\circ} \mathrm{N}$ to about $10 \mathrm{~m}$ under the weak winds near the coast of Mexico. These depths are above the thermocline everywhere in the region.

When the estimated Ekman velocities are subtracted from the observed drifter components, the remainder (Fig. 4, third row) should be comparable to the geostrophic currents from XBT data (Fig. 4, bottom row). The good agreement, in both velocity components, suggests that the geostrophic currents estimated here are consistent with the drifter data, and that the 450-m reference level is appropriate. Thus the three-dimensional circulation is reasonably well described by a simple model in which currents below the Ekman depth are considered to be purely geostrophic, with Ekman currents superimposed in a shallow surface layer.
Although the surface speeds in the NECC found from the drifters are faster than those indicated by geostrophy because of the Ekman contribution (Fig. 4), the Ekman transports are much smaller (by a factor of 5 or more) than the geostrophic transports because they occur in a thin layer. For example, in the case of the NECC weakening near $110^{\circ} \mathrm{W}$ (Fig. 3), the geostrophic NECC extends over more than $100 \mathrm{~m}$, whereas the Ekman depth $H_{*}$ is about $25 \mathrm{~m}$. Therefore the conclusion in section 4a that much of the NECC transport arriving in the region turns west near $110^{\circ} \mathrm{W}$ is not contradicted by the occurrence of rapid near-surface speeds detected by the drifters.

\section{c. Description of the wind}

As was the case with the thermocline topography and surface currents, the wind field also shows a distinct regime change from the central to the eastern Pacific. Again consider the situation at $120^{\circ} \mathrm{W}$ (Fig. 5). Southeasterlies blow across the equator, converging with trade-wind northeasterlies near $10^{\circ} \mathrm{N}$ into the ITCZ, with positive curl on the north flank of the convergence. This pattern is typical of the northern tropical Pacific all the way to the date line, with similar values of ITCZ curl. But looking farther east, the pattern is quite different. Instead of a zonally oriented ITCZ, the wind field (and especially the curl) is dominated by jets blowing through three gaps in the Central American cordillera: the Tehuantepec isthmus of Mexico, the Papagayo region of Nicaragua, and the low point where the Panama Canal was built (Fig. 5).

These wind jets extend at least $500 \mathrm{~km}$ into the Pacific and produce distinctive curl dipoles: each jet has a region of positive curl on its left flank and negative curl on its right. The magnitudes of these curls are at least as large as that of the ITCZ (more than twice as large within a few hundred kilometers of the coast). The positive curl on the south flank of the Papagayo jet is enhanced and extended to the west because east of $95^{\circ} \mathrm{W}$ the southerlies turn eastward after crossing the equator (Mitchell et al. 1989). A band of positive curl extends northeastward from the ITCZ to the coast of Mexico and is due to the strength of the northerlies increasing offshore (Fig. 5).

Short timescale variability of the mountain-gap wind jets (Hurd 1929; Chelton et al. 2000a,b) produces propagating and stationary eddies of various types (Roden 1961; Clarke 1988; McCreary et al. 1988; Barton et al. 1993; Giese et al. 1994; Trasviña 1995). Typically, largeamplitude jet events occur most often in the winter, and the Tehuantepec jet in particular is associated with synoptic midlatitude weather systems transiting North America (Hurd 1929; Steenburgh et al. 1998; Chelton et al. 2000b). Since the jets can be very strong for periods of a few days, it is likely that nonlinearities in the ocean response to this episodic forcing rectify into the seasonal cycle and the mean, especially through strong mixing (McCreary et al. 


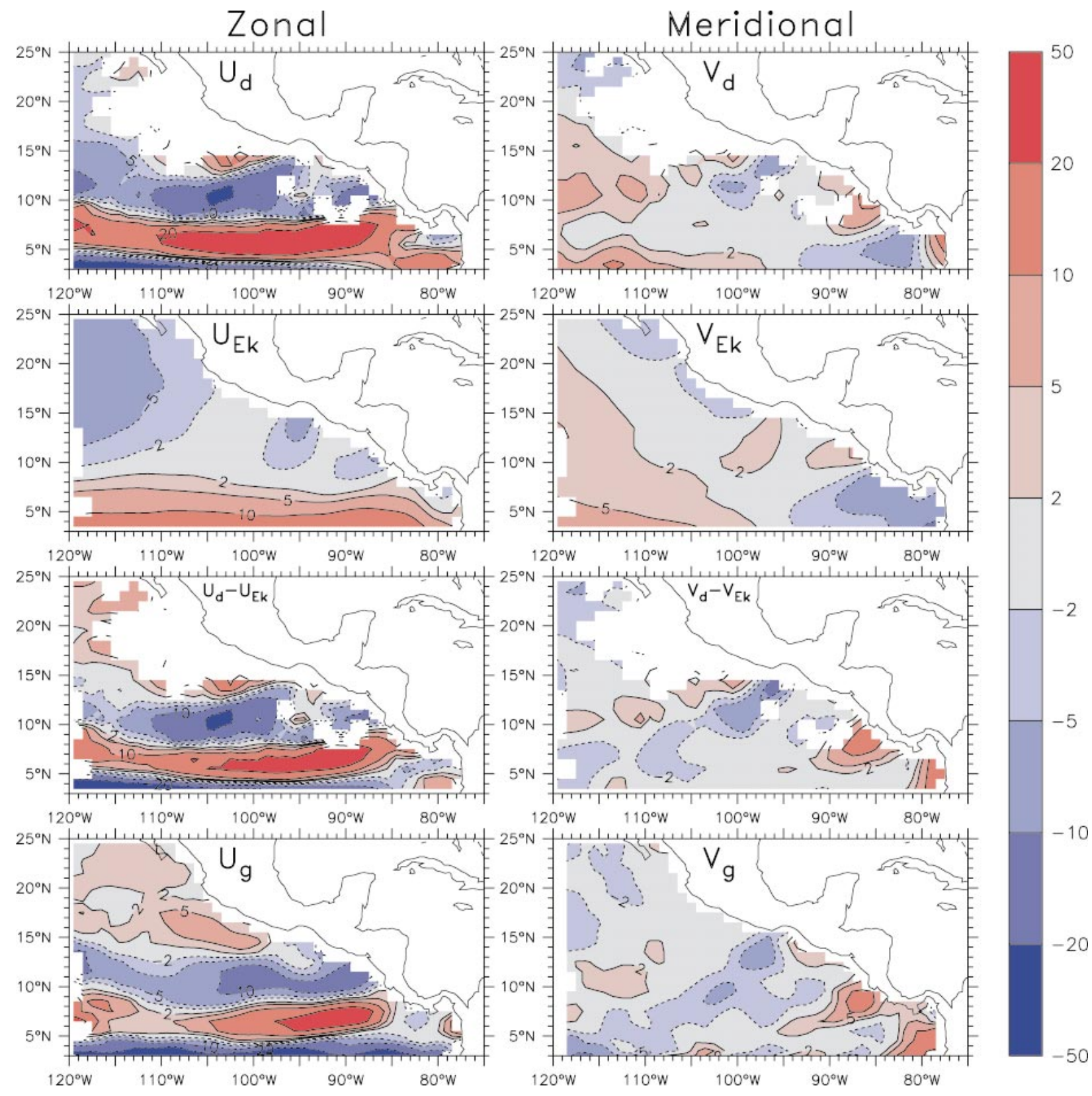

FIG. 4. Mean drifter, Ekman, and geostrophic near-surface currents $\left(\mathrm{cm} \mathrm{s}^{-1}\right)$ : (left panels) the zonal component and (right panels) the meridional component; (top panels) drifter velocity (blank areas indicate sparse or absent sampling); (second panels) Ekman velocity from the Quikscat winds with the Ekman depth estimated according to Ralph and Niiler (1999; see section 4b); (third panels) drifter minus Ekman velocities; (bottom panels) geostrophic velocities.

1989) and latent heat fluxes. These nonlinear effects are not encompassed by the dynamical formulation developed in section 3 and therefore are a source of uncertainty in the interpretation below.

\section{d. Dynamical interpretation}

\section{1) Vertically integRAted Flow}

Figure 6 compares the two sides of Eq. (2), the Sverdrup balance. The upper panel (from the ocean data) is the vertically integrated meridional geostrophic transport/unit width, scaled by the Coriolis parameter. The lower panel (the Ekman pumping velocity estimated from the wind data) is similar to the curl field shown in Fig. 5, except that $\operatorname{curl}(\tau / f)$ includes a term proportional to the zonal wind stress [see the discussion leading up to Eq. (2)]. An important difference in the pattern of $\operatorname{curl}(\tau / f)$, compared to that for $\operatorname{curl}(\tau)$, is the enlargement of the region of downwelling curl on the right flank of the Tehuantepec jet, extending this southwest- 


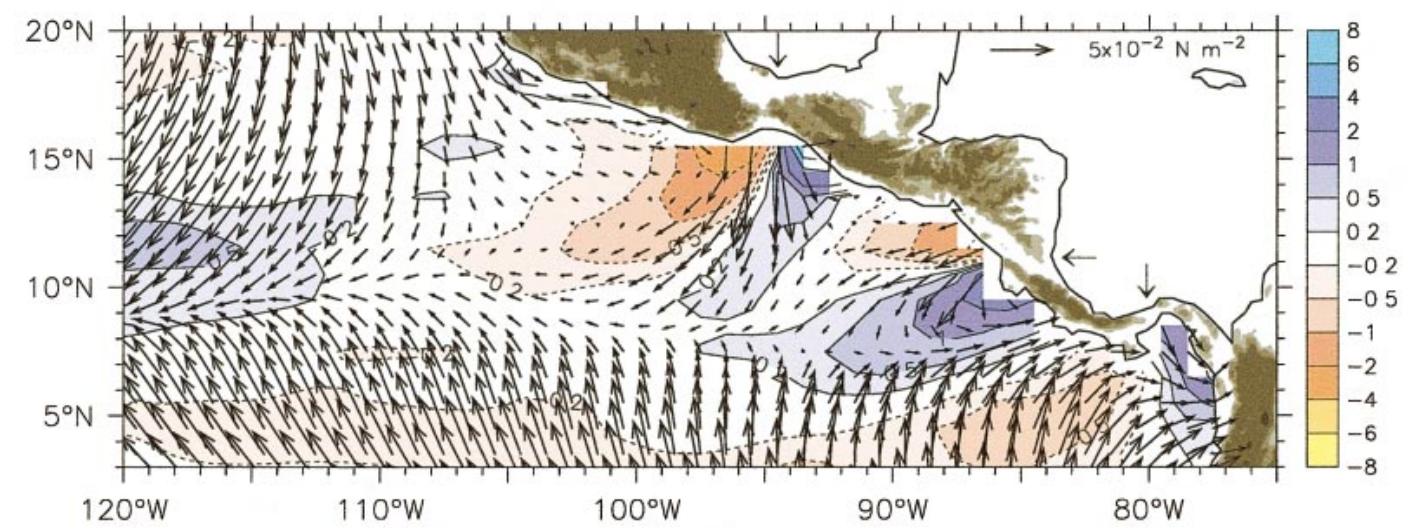

FIG. 5. Mean wind stress vectors and curl (colors) averaged over Aug 1999-Jul 2000. Red shading shows negative (downwelling) curl and blue positive (upwelling) curl, in units of $10^{-7} \mathrm{~N} \mathrm{~m}^{-3}$, with (stretched) color key at right. The scale vector $\left(5 \times 10^{-2} \mathrm{~N} \mathrm{~m}^{-2}\right)$ is located in the Caribbean. The gray shading on land indicates altitudes greater than $250 \mathrm{~m}$. The three mountain gaps referred to in the text are marked with arrows on the Caribbean side; from north to south these are denoted the Isthmus of Tehuantepec, the Gulf of Papagayo, and the Gulf of Panama.

ward to form a continuous NE-SW band. This extension occurs because of the relatively strong easterly stress $\left(\tau^{\times}<0\right)$ in this region (vectors in Fig. 5).

The Sverdrup balance comparison (Fig. 6) generally confirms that these linear dynamics describe the main features of the vertically integrated ocean response to the distinctive wind forcing in this region. Ekman upwelling is balanced by poleward geostrophic flow,

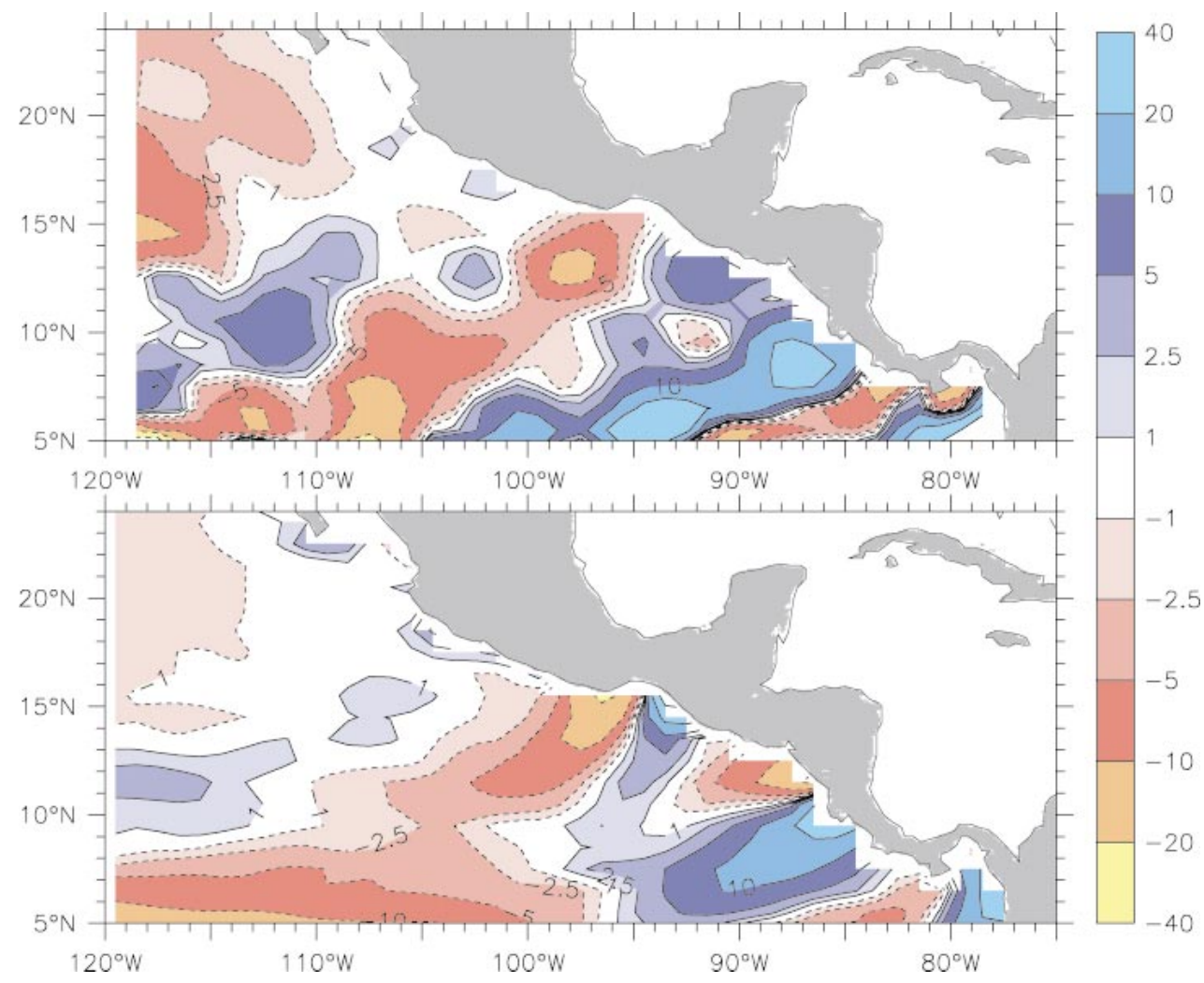

FIG. 6. Sverdrup balance comparison [lhs and rhs of Eq. (2)]: (top panel) the "ocean term" ( $\left.\beta / f \int v_{g} d z\right)$ calculated from the XBT data; (bottom panel) the "wind term" $(\operatorname{curl}(\tau / \rho f))$ calculated from the wind data (both in units of $\mathrm{m} \mathrm{month}^{-1}$ ). Blue shading indicates poleward transport and upwelling curl in the top and bottom panels, respectively; red shading is equatorward transport and downwelling curl. The color key for both quantities is at right. 
downwelling by equatorward flow. All features of the wind, including the three curl dipoles due to the mountain-gap winds, the southwestward extension of the Tehuantepec downwelling curl, and the upwelling band due to the ITCZ, clearly have been imprinted on the ocean and are visible in the circulation.

Several discrepancies from the Sverdrup balance can be noted, however. The downwelling curl on the north flank of the Papagayo jet (Fig. 6, bottom panel) is seen only as a weak feature in the ocean term (top panel). It may be that this inconsistency is due to poor sampling of the oceanic structure close to the coast (Fig. 1 shows that most of the XBT profiles were made offshore), but it is also possible that there are coastal phenomena or nonlinear eddy activity occurring that are not encompassed in the planetary-scale dynamics studied here. Second, the Papagayo upwelling curl extends only to $96^{\circ} \mathrm{W}$ (Fig. 6, bottom), whereas the oceanic poleward flow is seen considerably farther west along the southern edge of the region (top). One possible explanation is interannual variability not sampled by the single year of Quikscat winds. In this region (Fig. 5) $\operatorname{curl}(\tau)$ is weak, so the pattern shown in Fig. 6 (bottom) is strongly influenced by the $\tau^{\times}$term of $\operatorname{curl}(\tau / f)$, the effect of which is amplified close to the equator by its $f^{-2}$ dependence. The change of $\operatorname{sign}$ of $\operatorname{curl}(\tau / f)$ is thus due mostly to the split of the southerlies (Fig. 5). Some other wind products (especially the ERS winds) that represent more than the single year of Quikscat show this split occurring further west, more in agreement with the XBT-derived ocean circulation, so this may reflect a time-dependent feature that is not resolved by Quikscat. A more likely possibility is the existence of an equatorward flow at deeper levels than sampled by the XBTs. This is suggested by the fact that the meridional geostrophic current at $500 \mathrm{~m}$ relative to $1000 \mathrm{~m}$ calculated from the Levitus et al. (1994) atlas is southward in the region from $95^{\circ} \mathrm{W}$ to $102^{\circ} \mathrm{W}$, just where the two panels of Fig. 6 disagree. When this current is added to the XBT fields used to construct the top panel of Fig. 6, the discrepancy is much reduced. However, a caution is that there is really very little data making up the deeper Levitus (1994) fields in this region, so there is no definitive check. Finally, the equatorward flow north of $13^{\circ} \mathrm{N}$ and west of about $110^{\circ} \mathrm{W}$ (Fig. 6, top) is stronger by a factor of 2 or more than would be implied by the winds, and the reason for this is not known.

Despite these discrepancies, overall, the simple dynamics of the Sverdrup balance seem to describe the forced ocean circulation in the northeastern tropical Pacific reasonably well, especially given the nonsimultaneous ocean and atmosphere measurements and the other sources of error that have been mentioned above. This suggests several implications for the distinctive thermocline topography and currents of this region, which will be discussed below.

\section{2) Surface circulation}

In section $4 \mathrm{a}$, it was noted that the thermocline trough along $14^{\circ} \mathrm{N}$ and the ridge along $9^{\circ} \mathrm{N}$ both weakened near $110^{\circ} \mathrm{W}$, with the consequence that the NECC also weakened there [see Figs. 2(bottom) and 3]. The Ekman pumping map (Fig. 6, bottom) suggests that these features are consistent with the Sverdrup dynamics discussed above, expressed through curl-modulated thermocline topography. Much [but not all; important exceptions will be diagnosed in section 4d(3)] of the Z20 variations can be ascribed to this mechanism, with upwelling curl observed where the thermocline slopes up to the west, downwelling curl where it slopes down. (Note that in these planetary dynamics, it is the zonal slope of the thermocline, not the Z20 value itself, that is expected to correspond to the Ekman pumping.) The band of downwelling $\operatorname{curl}(\tau / f)$ stretching southwestward from the Gulf of Tehuantepec (Fig. 6, bottom) overlies the westward deepening of Z20 that strengthens the two thermocline troughs and weakens the ridge (Fig. 2 , bottom), and the band of upwelling $\operatorname{curl}(\tau / f)$ that curves southwestwards from the coast of Mexico at $18^{\circ} \mathrm{N}, 104^{\circ} \mathrm{W}$ overlies the westward shoaling of Z20 that has the opposite effect. That these are perturbations associated principally with thermocline topography is confirmed by the fact that the meridional geostrophic currents which comprise the transports shown in Fig. 6, (top) along these bands arise only in the thermocline and above. Therefore, the weakening of the NECC near $110^{\circ} \mathrm{W}$ (Fig. 3) appears to be a straightforward result of Ekman pumping, and the northward turning of this current into the NEC reflects the associated planetary vorticity conservation. Such thermocline pumping is typical of much of the tropical Pacific, which to a first approximation acts as a single active layer overlying a nearly motionless abyss (Kessler and Taft 1987). In this case it is realistic to think of the curl forcing simply pumping the thermocline to reach Sverdrup balance. However, some other parts of this region have a richer vertical structure, which is the subject of the next section.

\section{3) Subthermocline Circulation}

One region where thermocline topography is insufficient to account for the meridional currents needed to conserve planetary potential vorticity is on the western side of the Costa Rica Dome. Surface geostrophic currents (Fig. 3) are consistent with Z20 (Fig. 2, bottom) in showing the dome as a closed-contour cyclonic eddy, with southward surface flow on its west side. Yet the Ekman pumping and meridional integrated transports (Fig. 6) indicate strong northward transport across the extent of the dome. A zonal section along $8.5^{\circ} \mathrm{N}$ (through the center of the dome and approximately along the thermocline ridge) shows that the thermocline slopes are not the whole story in this region (Fig. 7). 


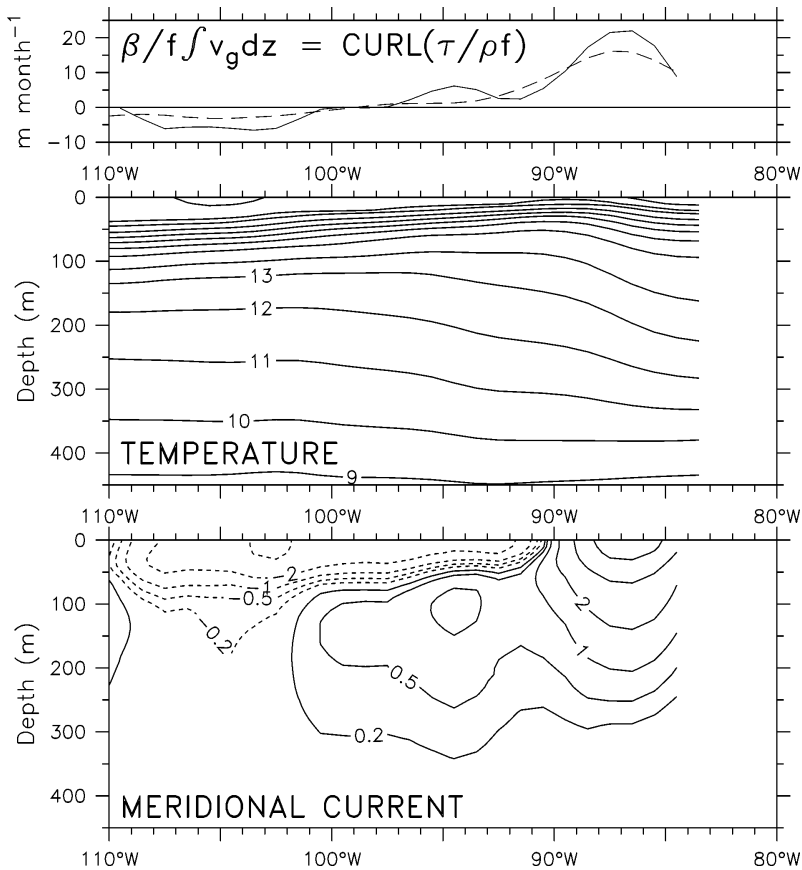

FIG. 7. Zonal section of the Sverdrup balance, $T(z)$ and $v_{g}(z)$ along $8.5^{\circ} \mathrm{N}$. The coast is at $83^{\circ} \mathrm{W}$. (top panel) The "ocean term" (solid line) and "wind term" (dashed line) of the Sverdrup balance [see Eq. (2)]. (middle panel) The temperature from the surface to $450 \mathrm{~m}$; the contour interval is $1^{\circ} \mathrm{C}$ from $8^{\circ}$ to $14^{\circ} \mathrm{C}, 2^{\circ} \mathrm{C}$ from $16^{\circ}$ to $26^{\circ} \mathrm{C}$, and $1^{\circ} \mathrm{C}$ from $27^{\circ}$ to $29^{\circ} \mathrm{C}$. (bottom panel) The meridional geostrophic current from the surface to $450 \mathrm{~m}$; northward flow is indicated by solid contours, southward by dashed contours; the contour interval is every $5 \mathrm{~cm} \mathrm{~s}^{-1}$ within $\pm 15 \mathrm{~cm} \mathrm{~s}^{-1}$, then \pm 1 and $2 \mathrm{~cm} \mathrm{~s}^{-1}, \pm 0.5$ $\mathrm{cm} \mathrm{s}^{-1}$, and $\pm 0.2 \mathrm{~cm} \mathrm{~s}^{-1}$.

The Sverdrup balance does largely balance along the section (Fig. 7, top). The dome is seen as an extremely shallow structure, with the tight thermocline coming very close to the surface near $89^{\circ} \mathrm{W}$ (Fig. 7 , middle), and oppositely directed currents forming the cyclonic eddy only above $50 \mathrm{~m}$ (Fig. 7, bottom). However, subthermocline isotherms slope upward to the west under the entire dome (and even farther to the west). For example, $12^{\circ} \mathrm{C}$ rises westward until about $104^{\circ} \mathrm{W}$. This change of slope produces the strongly sheared meridional geostrophic currents, with northward flow beneath both northward and southward limbs of the surface eddy (Fig. 7, bottom). The vertically integrated transport is northward, consistent with the Sverdrup balance and as shown in Fig. 6. This can be interpreted according to (2): the Ekman upwelling over the dome lifts the thermocline and thereby stretches the subthermocline water column, which must move poleward to conserve its potential vorticity. (It is also argued below that there is significant upwelling through the thermocline into the upper layer).

A map of transport between the 450-m reference level and the bottom of the thermocline (Fig. 8) shows the northward flow beneath the Costa Rica Dome (Fig. 7) to be the northern Subsurface Countercurrent or "Tsu-

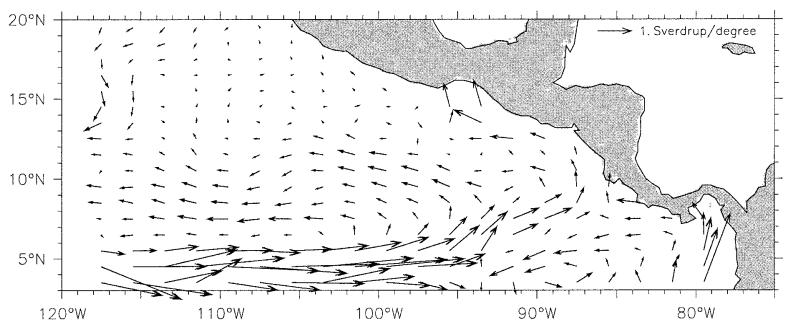

FIG. 8. Geostrophic transport vectors integrated from the 450-m reference level to the $17^{\circ} \mathrm{C}$ isotherm (base of the thermocline). The scale vector (1 Sverdrup per degree) is located in the Caribbean.

chiya Jet" (Tsuchiya 1975; Johnson and Moore 1997; Johnson and McPhaden 1999; Rowe et al. 2000) turning sharply away from the equatorial region after having traversed the entire basin along $2^{\circ}-5^{\circ} \mathrm{N}$. The eastward Tsuchiya Jet transport in this layer is about $6 \mathrm{~Sv}(\mathrm{~Sv} \equiv$ $10^{6} \mathrm{~m}^{3} \mathrm{~s}^{-1}$ ) between $2.5^{\circ} \mathrm{N}$ and $5.5^{\circ} \mathrm{N}$ at all longitudes west of $100^{\circ} \mathrm{W}$, slightly smaller than other estimates, probably because of the too-shallow reference level available from XBTs.

It is apparent from Fig. 8 that more water flows into the region in the Tsuchiya jet than flows out horizontally. After turning north from about $5^{\circ} \mathrm{N}$ to about $8^{\circ} \mathrm{N}$, the jet turns west in the lower reaches of the NEC in a current that is somewhat broader, but much weaker than the incoming eastward jet. The westward flow has a transport of about $3.5 \mathrm{~Sv}$, about $2.5 \mathrm{~Sv}$ less than the eastward inflow. Equation (4) can be used to estimate the upwelling through the base of the thermocline, by assuming $w$ is zero at $450 \mathrm{~m}$ and integrating (4) up to $17^{\circ} \mathrm{C}$. In order to estimate the transport through the $17^{\circ} \mathrm{C}$ isotherm, it is necessary to take into account the flow along the sloping isotherm; thus, the transport through $17^{\circ} \mathrm{C}$ is $w-\mathbf{u} \cdot \nabla h$, where $h$ is the $17^{\circ} \mathrm{C}$ surface (Fig. 9). Integrating this vertical transport horizontally over the region east of $105^{\circ} \mathrm{W}$, south of $12^{\circ} \mathrm{N}$, north of $3.5^{\circ} \mathrm{N}$, and northwest of the line from $3.5^{\circ} \mathrm{N}, 92.5^{\circ} \mathrm{W}$ to $8.5^{\circ} \mathrm{N}$, $82.5^{\circ} \mathrm{W}^{\circ}$ (outlined in Fig. 9) gives a cross-isotherm transport of about $3.5 \mathrm{~Sv}$, somewhat more than necessary to account for the net inflow in the subthermocline layer due to the Tsuchiya jet. This suggests a consistent

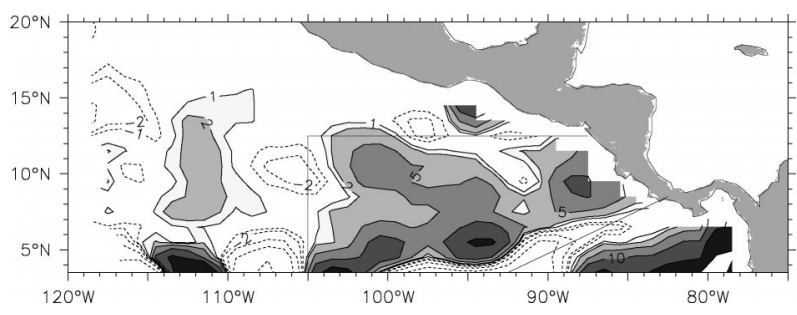

FIG. 9. Geostrophic transport across the $17^{\circ} \mathrm{C}$ isotherm $(w-\mathbf{u}$. $\boldsymbol{\nabla} h$ ) in units of $\mathrm{m}$ month ${ }^{-1}$, where $w$ is estimated from Eq. (4), $\mathbf{u}$ is the geostrophic current on the isotherm, and $h$ is the isotherm depth. Shaded areas (line contours) show upwelling across the isotherm; dashed contours show downwelling. The overlaid line outlines the area over which upwelling was integrated. 


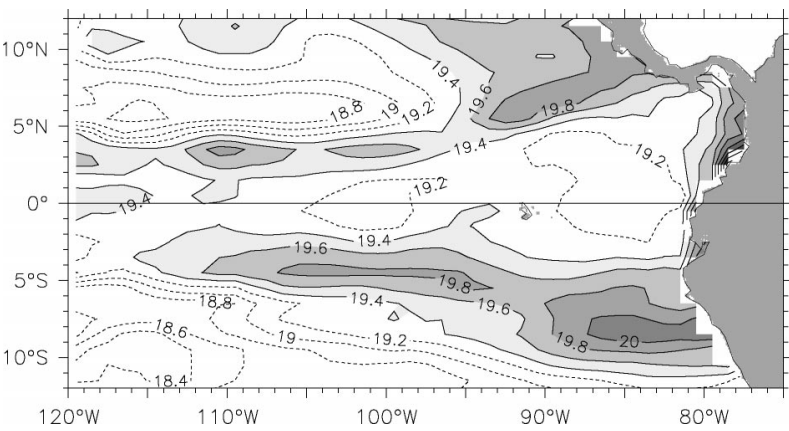

FIG. 10. Dynamic height at $300 \mathrm{~m}$ relative to $450 \mathrm{~m}$ between $12^{\circ} \mathrm{S}$ and $12^{\circ} \mathrm{N}$. Shaded areas show high dynamic height, dashed contours demonstrate low dynamic height (the contour interval is $0.2 \mathrm{dyn} \mathrm{cm}$ ).

picture of strong Ekman divergence in the surface layer pulling water through the extremely shallow thermocline of the Costa Rica Dome, causing the lower layer to stretch vertically, and hence to move poleward conserving its potential vorticity. As a consequence, the Tsuchiya jet is pulled away from the equator.

Of course this transport estimate is a crude approximation. The reference level could introduce errors, and it was suggested in section $4 \mathrm{~d}(1)$ above that the northward flow near $100^{\circ} \mathrm{W}$ may be overestimated because of a too-shallow reference level. In addition, the difficulty of computing geostrophic flow closer than $3^{\circ}$ lat from the equator means that the possibility that part of the Tsuchiya jet in fact turns southward in this region, as has been argued from water property distributions by Rowe et al. (2000), cannot be evaluated here. Either of these problems would tend to reduce the estimated upwelling transport; however, the dynamical consistency of the entire picture suggests that it is at least qualitatively correct.

A less well-known subthermocline current appears in the transport map (Fig. 8), flowing northward along the coast of Colombia into the Gulf of Panama, then turning southwestward back toward the equator just southeast of the Tsuchiya jet. Although it is found quite deep (its shear is strong even at the lowest XBT depth of 450 $\mathrm{m})$, this transport also obeys the Sverdrup balance (Fig. $6)$, being due to the curl dipole associated with the wind jet into the Gulf of Panama and the westerly winds nearer to the equator (Fig. 5). Interestingly, this subthermocline structure is approximately symmetric across the equator, with dynamic height ridges stretching southwestward from the coast at about $8^{\circ} \mathrm{S}$ and $9^{\circ} \mathrm{N}$ to about $\pm 3^{\circ}$ latitude, $110^{\circ} \mathrm{W}$, below $300 \mathrm{~m}$ (Fig. 10). The two Tsuchiya jets flow east on the poleward flank of these ridges, while on the equatorward sides of the ridges the unnamed currents appear to emerge from an equatorial divergence at the coast, flow poleward along the coast, then westward and equatorward. Although these westward flows are continuous with the SEC above the thermocline, the connection between them is unclear. This structure is seen in the $110^{\circ} \mathrm{W}$ meridional section of ADCP zonal current in Rowe et al. (2000) (their Fig. 1). However, the horizontal pattern in Fig. 10 differs from the Rowe et al. schematic circulation (their Fig. 11 ) in showing the westward flow originating from the eastern boundary near the equator, whereas they suggest an origin in the Tsuchiya jets. Rowe et al.'s inference was not based on observed meridional currents (nor did they have any observations near the coast) but on the necessity for a convergence into the region in the east. The XBT dynamic heights shown in Fig. 10 suggest that the needed convergence occurs near the equator, and is not an inflow from higher latitudes.

\section{Summary and discussion}

A compilation of historical XBT data is used to construct the mean thermal structure and associated geostrophic flow in the northeastern tropical Pacific, and is diagnosed based on linear dynamics forced with satellite scatterometer winds. The mean geostrophic circulation is consistent with the Sverdrup balance (Fig. 6), driven principally by the three wind jets blowing through the gaps in the Central American cordillera. This is surprising because previous work has emphasized the prominence of nonlinear processes for the time-dependent flows of this region, driven by the same winds. The gap winds produce distinct patterns of curl (a dipole of positive and negative curl flanking each jet) that imprint on the ocean thermal structure and thereby determine the circulation. The results of this forcing include distortion of the familiar zonal currents of the central tropical Pacific, and imply a significant vertical (crossisotherm) transport.

In the central Pacific, zonal scales are very long and spatial variation of the wind is primarily a function of latitude alone, especially the basin-width band of positive wind stress curl associated with the ITCZ, which drives the NECC (Sverdrup 1947). By contrast, in the east the mountain-gap winds produce strong zonal gradients of curl. Bands of downwelling and upwelling curl extend southwestward from Tehuantepec and Papagayo respectively, and the positive curl marking the southern boundary of the trades turns northeastward from the ITCZ near $110 \mathrm{~W}^{\circ} \mathrm{W}$ (Fig. 5). These bands alternately weaken and strengthen the ridge-trough system that supports the NEC and NECC, producing the relatively isolated Costa Rica Dome near $9^{\circ} \mathrm{N}, 90^{\circ} \mathrm{W}$, a Tehuantepec bowl near $14^{\circ} \mathrm{N}, 105^{\circ} \mathrm{W}$, and a pronounced reduction in the thermocline slope that supports the NECC near $110^{\circ} \mathrm{W}$ (Fig. 2, bottom). Because of these zonal thermocline slopes, the geostrophic NECC nearly disappears at $110^{\circ} \mathrm{W}$, with much of its transport turning around into the NEC well west of the coast, so that flow around the Costa Rica Dome is only partly fed by the NECC and instead can come from further north along the coast of Mexico (Fig. 3). The Ekman transport, however, is eastward because of the prevailing southerly winds south of $8^{\circ} \mathrm{N}$ (Fig. 5), producing eastward near- 
surface flow above the disappearing geostrophic NECC; this is well-sampled by the $15-\mathrm{m}$ drogued drifters (Fig. 4).

In addition to the effects of Ekman pumping on thermocline topography, the linear diagnosis suggests additional implications for the deeper flows. Below the thermocline, isotherms slope upwards to the west under the entire Costa Rica Dome, implying northward flow beneath the surface eddy (Fig. 7). This can be understood as a result of stretching of the water column by Ekman upwelling above the dome: the column must move poleward to conserve its planetary potential vorticity. The amount of upwelling reaching through the thermocline can be estimated according to this principle as stated in Eq. (4), integrating upwards from a reference level where $w$ and $v$ are assumed to be zero. At the base of the thermocline (about $17^{\circ} \mathrm{C}$ ) the cross-isotherm transport $(w-\mathbf{u} \cdot \boldsymbol{\nabla} h)$ is about $3.5 \mathrm{~Sv}$ over the region of upwelling (Fig. 9). This estimate is roughly consistent with the apparent loss of volume transport in the subthermocline layer, where the northern Tsuchiya jet enters the region with a transport of about $6 \mathrm{~Sv}$ but only about 3.5 Sv flows out (Fig. 8).

The fact that the vertically integrated volume transport is only partly associated with thermocline topography is one reason why efforts to model this region of the ocean with single-active-layer models have been difficult to interpret (e.g., Hofmann et al. 1981). Such models, forced with observed winds, necessarily represent the total transport as being due to variations of the single interface. The Costa Rica Dome, however, is an extremely shallow feature (Fig. 7), with the result that the wind-driven (Sverdrup) transport is not just the tight eddy found at the surface, but instead is an integration over a strongly sheared system (the closed-contour eddy shown in Fig. 3 and the purely northward subthermocline flow in Fig. 8). Clearly, at least a 2.5-layer formulation is necessary to model this situation.

It is noteworthy that the vertical transport through $17^{\circ} \mathrm{C}$ shown in Fig. 9 is dominated by upwelling, with only a few small areas of downwelling. This pattern contrasts with the same quantity integrated all the way to the surface (Fig. 6, top), which has an approximately equal amount of each sign of vertical velocity over the region. From one point of view this simply expresses the fact that the subthermocline velocities are predominantly poleward, with equatorward currents found above the thermocline. However, the implication is that the Ekman downwelling involves only the near-surface layer (deepening the thermocline but not pushing water down through it), while the upwelling can extend through the thermocline to draw water from the lower layer. One interpretation could be that it is only when the thermocline is shallow enough for surface mixing to reach through it that the subthermocline layer can be involved, and of course this will usually be in upwelling situations. In areas of the ocean where subduction occurs (for example in parts of the eastern subtropical gyres and in subpolar regions) the mechanism is usually deep winter mixing followed by summer restratification and the creation of a "fossil" mixed layer with upper layer water isolated from the surface, not direct Ekman downwelling through the thermocline.

A new model of the Tsuchiya jets describes the above behavior quantitatively, simulating realistic thermostadlayer isotherm slopes along the ITCZ (McCreary et al. 2002). In this model, upwelling is transmitted to the subthermocline layer when the surface layer becomes thin enough, and lower layer thickness is determined by Rossby wave characteristics that are distorted by the Sverdrup currents, an extension of the theory of Luyten et al. (1983) and Luyten and Stommel (1986). Remarkably, McCreary et al. (2002) propose that Ekman suction in the east Pacific (including the Costa Rica Dome, the eastern ITCZ and the Peru coastal region) drives the Tsuchiya jets across the entire basin. In this model the water that upwells is ultimately supplied by the circulation around Australia, in which about $10 \mathrm{~Sv}$ of intermediate water enters the Pacific from the south, moves to the equator in the lower-level southern subtropical gyre, and then is distributed into the Tsuchiya jets in the far west. After flowing east in the Tsuchiya jets, it rises to the surface in the eastern upwelling regions and in the Northern Hemisphere enters the NEC, from which it leaves the Pacific in the upper layer via the Indonesian Throughflow. Thus, the $3.5 \mathrm{~Sv}$ of upwelling described here, which appears to be primarily a local phenomenon, may in fact be part of a much bigger picture in which the off-equatorial east Pacific upwelling is the doorway through which the subthermocline communicates with the surface layer in the Tropics. The fact that the Tsuchiya jet transport is larger than the upwelling it flows into (leaving about half the eastward transport to recirculate westward as shown in Fig. 8) is consistent with $\beta$-plume dynamics, in which a small upwelling can drive a large horizontal gyre (Stommel 1982).

Mean upwelling through the thermocline implies a large downward mixing of heat to maintain a steady state. It has proven difficult, however, to construct a mean heat balance in this region because the surface flux terms and the vertical structure of mixing (both of which are very likely time-dependent) are so poorly known. Since much of the mixing probably occurs episodically under the strong, short-term wind events (Barton et al. 1993), it cannot be estimated from the mean winds or diagnosed from the mean vertical temperature gradient. However, the cool SST spot directly above the center of the Costa Rica Dome (Fig. 2) does suggest that upwelling is a large cooling term here. As an isolated SST minimum, this feature cannot be due to horizontal advection, leaving vertical processes or air-sea fluxes. Wind speeds under the Papagayo jet are strong, so both wind stirring and latent heat fluxes are probably large cooling terms. However, the wind speed due to the Papagayo jet decreases rapidly offshore, with speeds over the dome being about two-thirds of those at the 
Quikscat grid point nearest the coast. The dome and cool SST spot actually lie under a relative minimum of mean wind speed. (Similarly, note that the cool region offshore of Tehuantepec extends only a short distance from the coast; Fig. 2, top.) Thus, it is difficult to argue that surface fluxes can account for the SST minimum, and the qualitative picture still suggests that the most likely explanation is vertical transport providing the bulk of the necessary cooling. It would be very desirable to understand the heat balance in the east Pacific warm pool because this region is where east Pacific tropical cyclones and hurricanes experience major growth (Whitney and Hobgood 1997; Zehnder et al. 1999). The extent to which the ocean horizontal and vertical circulations, and the effects of mixing and latent heat fluxes due to episodic wind events (including those due both to winter mountain-gap winds and summer hurricanes), contribute to interannual variability of SST in the region is not known. Disentangling these processes will probably require field studies with simultaneous observations of the atmosphere and (at least) the ocean mixed layer.

An early interpretation of the Costa Rica Dome upwelling was given by Wyrtki (1964), who noted the relatively high salinity and phosphate values in the center of the dome as an indication of emergence of subthermocline water. Wyrtki estimated the geostrophic current speed around the dome (similar to that found here) and calculated the gradient wind balance $\left(V^{2} / R+\right.$ $f V=-\partial p / \partial n$, where $V$ is the alongstream velocity, $R$ is the radius of curvature, and $\partial p / \partial n$ is the cross-stream pressure gradient). In this balance the pressure gradient is balanced both by Coriolis and by a centrifugal acceleration. This results in a cross-isobar divergence, integrated around the dome (and thus implying upwelling into the dome), of less then $0.1 \mathrm{~Sv}$, which was still thought to be a significant contribution to surface water properties. However, comparing the geostrophic term to the centrifugal term (the ratio of $f$ to $V / R$ ), for even generous values of $V\left(50 \mathrm{~cm} \mathrm{~s}^{-1}\right)$ and $1 / R\left[(200 \mathrm{~km})^{-1}\right]$, shows that the geostrophic term is about ten times larger, and the centrifugal acceleration is apparently not the primary reason for the upwelling.

Several questions can be raised regarding the uncertainty due to inadequacies of the data sources used in this study. An important issue involves the use of historical XBT data to represent the mean of a highly timedependent field. The short timescale winds also produce short timescale features in the ocean that have been the subject of much work showing the occurrence of transient eddies, strong mixing, upwelling, and downwelling associated with the wind events (Roden 1961; Clarke 1988; McCreary et al. 1989; Giese et al. 1994; Trasviña 1995), and these features will certainly alias the sparsely sampled XBT profiles. In particular, one wonders whether the thermocline bowl seen near $14^{\circ} \mathrm{N}, 105^{\circ} \mathrm{W}$ is a true mean feature or is the result of sampling many short-term warm-core eddies. Of course, if the dynamics are truly linear then the sum of short-term forcing episodes is the equivalent of low-frequency forcing, but there is strong evidence for nonlinearity, at least on the timescales of the wind events (McCreary et al. 1989). A crude way to examine the possible effect of aliasing is to repeat the calculations using subsets of the data. That was done for the XBT data randomly sorted into two equal subsets; the mean thermocline portrayed by each half was very similar to Fig. 2 (bottom). We fall back on the a posteriori finding that the mean thermal structure, as estimated from the XBT data, is approximately in Sverdrup balance with the mean winds (Fig. 6 ), including the region of the Tehuantepec bowl, suggesting that whatever aliasing is taking place is not skewing the results excessively, and that a linear description of the mean is valid at least to first order.

In addition to the short timescale variability, there is also a large annual cycle of thermocline depth in the region that can be related to the wind stress curl signatures of the seasonal migration of the ITCZ and the winter maximum in mountain-gap wind occurrence (Fiedler 2002). While the Costa Rica Dome is evident throughout the climatological year, Fiedler shows that the thermocline is shallowest near the coast in late winter as a result of the Papagayo upwelling curl, and the dome grows offshore as the ITCZ moves north in summer. Thus, the forcing and dynamics of the seasonal cycle appear to be similar to those described here for the mean. The seasonal cycle of the northern Tsuchiya jet is less pronounced, but has a tendency to be stronger in boreal winter-spring (Johnson et al. 2002).

Although the Costa Rica Dome is shown here to be due to apparently particular features of the winds directed by the topography of Central America, in fact such domes appear in all of the analogous locations of the Atlantic and Pacific Oceans: in the South Pacific off Peru (although it has no surface expression) (Voituriez 1981), in the Atlantic (Mazeika 1967; Voituriez 1981; Yamagata and Iizuka 1995), and off the coasts of Guinea (Siedler et al. 1992) and Angola (Mazeika 1967). The Atlantic also has Tsuchiya jets (Tsuchiya 1986). Therefore, while the specific features of the Central American winds produce the distinctive details of the Costa Rica Dome, the fundamental reason for the occurrence of the dome and associated three-dimensional flow field appears to be a more general feature of the global circulation.

The ultimate and ongoing goal of this research is closure of the three-dimensional circulation in the eastern Pacific, which will be an essential element in diagnosing the heat budget and understanding the influences on SST in this climatically important region. While such a closure could not be achieved here, because of the limitations of working with sparsely sampled temperature data, a first step has been taken in demonstrating that upwelling occurs from beneath the thermocline into the surface layer. This connection suggests that the eastern off-equatorial Pacific (probably 
including the Peru upwelling as well) is a fundamental component of the general circulation of the Pacific.

Acknowledgments. The author learned a great deal in the course of discussions with Dudley Chelton, Meghan Cronin, Greg Johnson, Jay McCreary, Mike McPhaden, and as always, Dennis Moore, for which he is truly grateful. The XBT data were compiled and quality controlled by Dave Enfield, Maria Donoso, Jay Harris, and Pilar Cornejo at NOAA/AOML, and kindly made available by them. Dudley Chelton and Michael Schlax at OSU produced the Quikscat winds and curl smoothed and gridded precisely to my needs. TAO mooring data were obtained from the Web Site of the TAO Project Office at NOAA/PMEL. This work was funded by the NOAA Office of Global Programs through its Pan American Studies Program.

\section{REFERENCES}

Barton, E. D., and Coauthors, 1993: Supersquirt: Dynamics of the Gulf of Tehuantepec, Mexico. Oceanography, 6, 23-30.

Chelton, D. B., M. H. Freilich, and S. K. Esbensen, 2000a: Satellite observations of the wind jets off the Pacific coast of Central America. Part I: Case studies and statistical characteristics. Mon. Wea. Rev., 128, 1993-2018.

$\longrightarrow, \ldots$, and $—, 2000 \mathrm{~b}$ : Satellite observations of the wind jets off the Pacific coast of Central America. Part II: Regional relationships and dynamical considerations. Mon. Wea. Rev., 128, 2019-2043.

Clarke, A. J., 1988: Inertial wind path and sea surface temperature patterns near the Gulf of Tehuantepec and the Gulf of Papagayo. J. Geophys. Res., 93, 15 491-15 501.

Cromwell, T., 1958: Thermocline topography, horizontal currents and "ridging" in the eastern tropical Pacific. Bull. Inter-Amer. Trop. Tuna Comm., 3, 135-152.

Donoso, M. C., J. E. Harris, and D. B. Enfield, 1994: Upper ocean thermal structure of the eastern tropical Pacific. NOAA Tech. Rep. ERL-450-AOML-36, $221 \mathrm{pp}$.

Fiedler, P. C., 2002: The annual cycle and biological effects of the Costa Rica Dome. Deep-Sea Res., 49A, 321-338.

Giese, B. S., J. A. Carton, and L. J. Holl, 1994: Sea level variability in the eastern tropical Pacific as observed by TOPEX and the Tropical-Ocean Global Atmosphere Tropical-AtmosphereOcean Experiment. J. Geophys. Res., 99, 24 739-24 748.

Hansen, D. V., and G. A. Maul, 1991: Anticyclonic current rings in the eastern tropical Pacific Ocean. J. Geophys. Res., 96 (C4), 6965-6979.

—_ and P. M. Poulain, 1996: Quality control and interpolation of WOCE-TOGA drifter data. J. Atmos. Oceanic Technol., 13, 900-909.

Hayes, S. P., L. J. Mangum, J. Picaut, A. Sumi, and K. Takeuchi, 1991: TOGA-TAO: A moored array for real-time measurements in the tropical Pacific Ocean. Bull. Amer. Meteor. Soc., 72, 339347.

Hofmann, E. E., A. J. Busalacchi, and J. J. O'Brien, 1981: Wind generation of the Costa Rica Dome. Science, 214, 552-554.

Hurd, W. E., 1929: Northers of the Gulf of Tehuantepec. Mon. Wea. Rev., 57, 192-194.

Johnson, E. S., L. A. Regier, and R. A. Knox, 1988: A study of geostrophy in tropical Pacific Ocean currents during the NORPAX Tahiti shuttle using a shipboard Doppler acoustic current profiler. J. Phys. Oceanogr., 18, 708-723.

Johnson, G. C., and D. W. Moore, 1997: The Pacific equatorial subsurface countercurrents and an inertial model. J. Phys. Oceanogr., 27, 2448-2459.
, and M. J. McPhaden, 1999: Interior pycnocline flow from the subtropical to the equatorial Pacific Ocean. J. Phys. Oceanogr., 29, 3073-3098.

— B. M. Sloyan, W. S. Kessler, and K. E. McTaggart, 2002: Direct measurements of upper ocean currents and water properties across the tropical Pacific Ocean during the 1990's. Progress in Oceanography, Vol. 52, Pergamon, 31-61.

Kessler, W. S., 1990: Observations of long Rossby waves in the northern tropical Pacific. J. Geophys. Res., 95 (C4), 5183-5217. -, and B. A. Taft, 1987: Dynamic heights and zonal geostrophic transports in the central tropical Pacific during 1979-84. J. Phys. Oceanogr., 17, 97-122.

_ , and J. P. McCreary, 1993: The annual wind-driven Rossby wave in the subthermocline equatorial Pacific. J. Phys. Oceanogr., 23, 1192-1207.

Lagerloef, G. S. E., G. T. Mitchum, R. B. Lukas, and P. P. Niiler, 1999: Tropical Pacific near-surface currents estimated from altimeter, wind and drifter data. J. Geophys. Res., 104, $23313-$ 23326.

Landsteiner, M. C., M. J. McPhaden, and J. Picaut, 1990: Sensitivity of Sverdrup transport estimates to the specification of wind stress forcing in the tropical Pacific. J. Geophys. Res., 95, 1681-1691.

Levitus, S., R. Burgett, and T. P. Boyer, 1994: Salinity. Vol. 3, World Ocean Atlas 1994, NOAA Atlas NESDIS 3, 99 pp.

Luyten, J. R., and H. Stommel, 1986: Gyres driven by combined wind and buoyancy flux. J. Phys. Oceanogr., 16, 1551-1560.

_ J. Pedlosky, and H. Stommel, 1983: The ventilated thermocline. J. Phys. Oceanogr., 15, 292-309.

Mazeika, P. A., 1967: Thermal domes in the eastern tropical Atlantic Ocean. Limnol. Oceanogr., 12, 537-539.

McCreary, J. P., H. S. Lee, and D. B. Enfield, 1989: Response of the coastal ocean to strong offshore winds: With application to circulations in the Gulf of Tehuantepec and Papagayo. J. Mar. Res. 47, 81-109.

_- P. Lu, and Z.-J. Yu, 2002: Dynamics of the Pacific subsurface countercurrents. J. Phys. Oceanogr., 32, 2379-2404.

McPhaden, M. J., and R. A. Fine, 1988: A dynamical interpretation of the tritium maximum in the central equatorial Pacific. J. Phys. Oceanogr., 18, 1454-1457.

—_ and Coauthors, 1998: The TOGA observing system: A decade of progress. J. Geophys. Res., 103, 14 169-14 240.

Meyers, G., 1980: Do Sverdrup transports account for the Pacific North Equatorial Countercurrent? J. Geophys. Res., 85, 10731075.

Mitchell, T. P., C. Deser, and J. M. Wallace, 1989: The influence of sea surface temperature on surface wind in the eastern equatorial Pacific: Seasonal and interannual variability. J. Climate, 2, 15001506

Niiler, P. P., A. S. Sybrandy, K. Bi, P. M. Poulain, and D. Bitterman, 1995: Measurements of the water-following capability of holeysock and TRISTAR drifters. Deep-Sea Res., 42, 1951-1964.

Picaut, J., and R. Tournier, 1991: Monitoring the 1979-1985 equatorial Pacific current transports with expendable bathythermograph data. J. Geophys. Res., 96, 3263-3277.

Ralph, E. A., and P. P. Niiler, 1999: Wind-driven currents in the tropical Pacific. J. Phys. Oceanogr., 29, 2121-2129.

Reverdin, G., C. Frankignoul, E. Kestenare, and M. McPhaden, 1994: Seasonal variability of the surface currents of the equatorial Pacific. J. Geophys. Res., 99, 20 323-20 344.

Reynolds, R. W., and T. M. Smith, 1994: Improved global sea surface temperature analyses using optimum interpolation. J. Climate, 7, 929-948.

Roden, G. I., 1961: On the wind-driven circulation in the Gulf of Tehuantepec and its effect upon surface temperatures. Geofis. Int., 1, 55-72.

Rowe, G. D., E. Firing, and G. C. Johnson, 2000: Pacific equatorial subsurface countercurrent velocity, transport, and potential vorticity. J. Phys. Oceanogr., 30, 1172-1187.

Schlax, M. G., D. B. Chelton, and M. H. Freilich, 2001: Sampling 
errors in wind fields constructed from single and tandem scatterometer datasets. J. Atmos. Oceanic Technol., 18, 1014-1036.

Siedler, G., N. Zangenberg, R. Onken, and A. Morlière, 1992: Seasonal changes in the tropical Atlantic circulation: Observation and simulation of the Guinea Dome. J. Geophys. Res., 97 (C1), 703-715.

Steenburgh, W. J., D. M. Schultz, and B. A. Cole, 1998: The structure and evolution of gap outflow over the Gulf of Tehuantepec, Mexico. Mon. Wea. Rev., 126, 2673-2691.

Stommel, H., 1982: Is the South Pacific helium-3 plume dynamically active? Earth Planet. Sci. Lett., 61, 63-67.

Sverdrup, H. U., 1947: Wind-driven currents in a baroclinic ocean, with application to the equatorial currents of the eastern Pacific Proc. Natl. Acad. Sci. USA, 33, 318-326.

Taft, B. A., and W. S. Kessler, 1991: Variations of zonal currents in the central tropical Pacific during 1970 to 1987: Sea level and dynamic height measurements. J. Geophys. Res., 96, 12 599-12 618.

Trasviña, A., 1995: Offshore wind forcing in the Gulf of Tehuantepec, Mexico: The asymmetric circulation. J. Geophys. Res., 100 (C10), 20 649-20663.

Tsuchiya, M., 1975: Subsurface countercurrents in the eastern equatorial Pacific Ocean. J. Mar. Res., 33 (Suppl.), 145-175.

- 1986: Thermostads and circulation in the upper layer of the Atlantic Ocean. Progress in Oceanography, Vol. 16, Pergamon, 235-267.

Umatani, S., and T. Yamagata, 1991: Response of the eastern tropical
Pacific to meridional migration of the ITCZ: The generation of the Costa Rica Dome. J. Phys. Oceanogr., 21, 346-363.

Voituriez, B., 1981: Les sous-cournats équatoriaux nord et sud et la formation des dômes thermiques tropicaux. Oceanol. Acta, 4, 497-506.

Whitney, L. D., and J. S. Hobgood, 1997: The relationship between sea surface temperatures and maximum intensities of tropical cyclones in the eastern North Pacific Ocean. J. Climate, 10, 2921-2930.

Wyrtki, K. 1964: Upwelling in the Costa Rica Dome. Fish. Bull., 63, 355-372.

_ 1966: Oceanography of the eastern equatorial Pacific Ocean. Oceanogr. Mar. Biol., 4, 33-68.

_- 1967: Circulation and water masses in the eastern equatorial Pacific Ocean. Int. J. Oceanol. Limnol., 1, 117-147.

__ 1975: Fluctuations of the dynamic topography in the Pacific Ocean. J. Phys. Oceanogr., 5, 450-458.

_- and B. Kilonsky, 1984: Mean water and current structure during the Hawaii-to-Tahiti shuttle experiment. J. Phys. Oceanogr., 14, 242-254.

Yamagata, T., and S. Iizuka, 1995: Simulation of the tropical thermal domes in the Atlantic: A seasonal cycle. J. Phys. Oceanogr., 25, 2129-2140.

Zehnder, J. A., D. M. Powell, and D. L. Ropp, 1999: The interaction of easterly waves, orography, and the intertropical convergence zone in the genesis of eastern Pacific tropical cyclones. Mon. Wea. Rev., 127, 1566-1585. 